DOI 10.37882/2223-2982.2020.06.01

\title{
ВАРИАТИВНОСТЬ СИНТАКСИЧЕСКИХ ЕДИНИЦ НА ОСНОВЕ МОДЕЛИРОВАНИЯ СЕМАНТИЧЕСКОЙ СТРУКТУРЫ ПРЕДЛОЖЕНИЯ В РЕЧЕВОЙ КОММУНИКАЦИИ
}

\section{VARIATION OF SYNTACTIC UNITS BASED ON MODELING THE SEMANTIC STRUCTURE OF A SENTENCE IN SPEECH COMMUNICATION}

\section{T. Abdukadyrova \\ M. Sakaeva}

Summary: The purpose of the article is to understand and scientifically substantiate the study of the variability of syntactic units based on the modeling of propositional semantics of a sentence.

The variability of language units at different levels reveals specific features due to changes in the ratio «invariant-variants». In particular, one of the debatable problems is the search for reasons for identifying the invariant. The semantic model of a sentence that reflects its semantic structure is implemented in one or more structural schemes.

The author confirms that when searching for reasons for selecting an invariant in the syntax, a comprehensive approach is necessary that takes into account to some extent all components of the sentence's meaning. Thus, when considering the variation in syntax, involving the identification offers both virtual and actual units arising from the implementation of a particular model in the act of verbal communication, it is necessary to take into account a number of semantic, structural-syntactic and textforming factors, reflecting verbosestatus the nature and terms of the internal and external contexts.

Keywords: variability, invariant, language units, semantics, syntax, speech communication, proposition, explicitness, implicitness, predicate actant.
Абдукадырова Тумиша Таштиевна к.п.н., дочент, Чеченский государственный университет, tumischa-uni@mail.ru

Сакаева Мата Вахитовна

Чеченский государственный университет, tumischa-uni@mail.ru

Аннотация: Целью статьи является осмысление и научное обоснование изучения вариативности синтаксических единиц на основе моделирования пропозитивной семантики предложения.

Вариативность языковых единиц разных уровней обнаруживает специфические черты, обусловленные изменением соотношения «инвариант-варианты». В частности, одна из дискуссионных проблем - поиск оснований для выявления инварианта.

Семантическая модель предложения, отражающая его смысловую структуру, реализуется в одной или нескольких структурных схемах.

Автор подтверждает то, что при поисках оснований для выделения инварианта в синтаксисе необходим комплексный подход, учитывающий в той или иной мере все компоненты значения предложения.

Таким образом, при рассмотрении варьирования в синтаксисе, предполагающем идентификацию предложения как виртуальной, так и актуальной единицы, возникающей в результате реализации определенной модели в акте речевой коммуникации, необходимо учитывать целый ряд семантических, структурно-синтаксических и текстообразующих факторов, отражающих вербоцентрическую природу предложения и условия внутреннего и внешнего контекстов.

Ключевые слова: вариативность, инвариант, языковые единицы, семантика, синтаксис, речевая коммуникация, пропозиция, эксплицитность, имплицитность, предикатный актант.
$\mathrm{B}$ современной лингвистике отмечается усиленное внимание к языку как средству коммуникации. При изучении функционирования языка и перехода от языка к речи нельзя обойти проблему языковой вариативности. Термином «вариативность» описываются различные языковые явления. Вариативность языковых единиц трактуется последователями двояко. В узком понимании этот термин применяется для характеристики формальных модификаций одной и той же единицы (формальное варьирование) или для описания вариантов значения при неизменности грамматической формы (семантическое варьирование). В широком понимании вариативность используется как способ существования и функционирования языковых единиц в синхронии. При этом выделяется основная единица значения - ин- вариант и его конкретные манифестации - варианты.

Вариативность языковых единиц разных уровней обнаруживает специфические черты, обусловленные изменением соотношения «инвариант-варианты». В частности, одна из дискуссионных проблем - поиск оснований для выявления инварианта. Попытки инвариантно-вариантного описания языковых единиц привели к образованию эмических и этических терминов, которые образуют пары: фонема - фон (аллофон), морфема - морф (алломорф) и т.д.

Выделение инварианта двусторонних единиц связано с проблемами семантики. Так, на морфологическом уровне схожие значения вариантов никак не соотносят- 
ся с действительностью. Морфологические варианты характеризуются прежде всего тождеством грамматической функции при различном формальном выражении [1, с 128].

В лексике инвариант выделяется в области лексической семантики и соотносится с понятием лексического множества [2, с.116]. Условием его выделения также тождество других компонентов значения слова - тождество общекатегориального (частеречного) и субкатегориального (значения слова как представителя подкласса обозначений конкретных предметов, явлений или процессов) значений.

Проблемы инвариантно-вариантного описания синтаксических единиц еще не нашли должного освещения в научной литературе. Одна из причин - сложность и неоднозначность самого объекта исследования. Спорными, требующими обсуждения остаются вопросы о конститутивной единице синтаксиса, о релевантном для синтаксиса уровне абстракции, о тождестве и различии синтаксических моделей и другие вопросы [3, с. 68].

Адекватное определение инвариантно-вариантных отношений на уровне предложения тормозится тем фактом, что чем сложнее единица, чем выше она находится в иерархии языковых уровней, тем труднее определить основания для выделения инварианта. Трудности возникают по крайней мере в двух направлениях.

Во-первых, стратификация языка предполагает подвижность сфер действия языковых единиц, их взаимосвязь и взаимодействие, что проявляется в участии единиц более низкого уровня в архитектонике единиц более высокого уровня. Так, варианты фонем формируют звуковую оболочку морфем и обусловливают вариативность на морфологическом уровне; варьирование морфем влечет за собой варьирование слов и т.д. Синтаксические конструкции формируются на базе лексико-семантических вариантов лексем, которые функционируют как слова-синтаксемы, характеризующие в первую очередь не индивидуальным (лексическим), а субкатегориальным значением, а также фиксацией одной из морфологических форм слова ка части речи [4, с. 47]. На языке этических терминов, следовательно, каждое предложение - это вариант вариантов языковых единиц более низких уровней, что подтверждает тезис о наличии в языке, как и в речевой коммуникации, лишь определенных манифестаций языковых единиц, которые могут быть отражены в языке в виде абстракции (инвариантов), а в речи - в виде их конкретизаций (вариантов). Одна из трудностей такого представления на уровне предложения заключается в том, что многие синтаксические явления имеют свою точку на другом уровне. Поэтому показатели вариативности иногда приходится искать в пограничных, «межуровневых», зонах языка [5, с.21]. Кроме того, варьирование предложения как комплексной единицы обусловлено вариативностью его составляющих - синтаксических единиц более низкого порядка: синтаксем, словосочетаний, глубинных падежей (функций аргументов) и т.д.

Во-вторых, содержательная сторона предложения, в области которой следует искать основания для выделения инварианта, включает в себя много компонентов (аспектов). В связи с этим сложилось большое число научных концепций, акцентирующих внимание на том или ином аспекте содержания предложения. В зависимости от того, какие уровни абстракции иерархично организованного значения синтаксических единиц признаются релевантными для выделения инварианта, решается вопрос о пределах синтаксического варьирования и разграничения синонимии и вариативности в синтаксисе.

Синтаксическим инвариантом могут служить структурные или семантические модели предложения. Структурная схема (модель) предложения как инвариант, выделенный в области синтаксического значения, проявляет определенное безразличие к лексическому заполнению позиций и в недостаточной мере отражает все многообразие языковой действительности [6, с.129]. Вопросы семантического моделирования предложения оказываются во многих случаях спорными, что говорит об их неразработанности. Тем не менее можно утверждать, что семантическая модель предложения, отражающая его смысловую структуру, реализуется в одной или нескольких структурных схемах.

Таким образом, сами структурные модели могут рассматриваться в качестве вариантов некоторого инварианта (семантической модели). Такой подход предполагает исследование разноструктурных единиц номинации, обозначающих один и тот же объект, явление или ситуацию: он пашет землю, тот, кто пашет землю; землепашеи, или пахарь [7, с.25].

Таким образом, при поисках оснований для выделения инварианта в синтаксисе необходим комплексный подход, учитывающий в той или иной мере все компоненты значения предложения.

На наш взгляд, наиболее полно поставленному выше требованию отвечает концепция моделирования семантической структуры предложения в виде предикатного выражения (пропозиция), состоящего из предиката и заполняющих его валентные позиции аргументов (семантических актантов). Вербоцентрическая концепция предложения нашла свое воплощение в исследовании синтаксических конструкций с глаголами определенных семантических классов. Изучение вариативности синтаксических единиц на основе моделирования пропозитивной семантики предложения, однако, усложняется 
тем, что синтаксические актанты семантики могут иметь предикатное значение [8, с.46].

Актанты с предикатным значением с семантической точки зрения представляют собой еще одну пропозицию в структуре конструкций с предикатным актантом и, следовательно, могут быть выражены единицами различной структурной сложности (словоформой, словосочетанием, инфинитивным оборотом, предикатным предложением).

Исходным пунктом моделирования препозитивной семантики вершинного глагола, от которой зависит в конечном счете поверхностно-синтаксическое оформление предложения. С семантической стороны группа предикатов, требующих сочетания с пропозицией (так называемые глаголы пропозиционального отношения), очень разнообразна - это интенциональные глаголы, т.е. глаголы, обозначающие психические акты: глаголы суждения и мышления, говорения и сообщения, памяти и знания, глаголы эмоциональных переживаний, оценочного суждения, волеизъявления, побуждения и др., глаголы чувственного восприятия [9, с. 146 ].

Проблема вариативности может быть рассмотрена отдельно в отношении предложений с вершинными глаголами различных семантических групп, так как от семантики глагола зависят количественные (наличие определенного числа вариантов) и качественные (структурная сложность) показатели вариативности.

В настоящей статье рассматриваются глаголы интенционального воздействия.

Группа глаголов интенционального воздействия выделяются по признаку двух схем: «интенциональности», под которой подразумевается психический акт, реализованный в акте речевой коммуникации, и «воздействия», означающий однонаправленность коммуникации на адресата [10,с. 239]. Сема «однонаправленность коммуникации на адресата» (в дальнейшем - сема «адресованности») выделена в противоположность семам «взаимной направленности речи» - с другой, например: дискутировать о чем-то с кем-то (двусторонняя направленность коммуникации, предполагающая обратную связь) - разговаривать во сне (направленная речь).

Сема «адресованности» есть во всех глаголах интенционального воздействия, но не всегда выражается эксплицитно. Очевидно, следует различать глаголы, в которых содержится сема «адресованности»:

а. всегда содержится имплицитно (popularisieren);

b. эксплицитно маркирована наличием адресата среди обязательных актантов предиката (j-n überreden);

c. по эксплицитности/имплицитности зависит от контекста (конкретность, определенность /абстрактность, неопределенность адресата и т.д.) (verlangen). Вариативное замещение позиции адресата - одна из сторон вариативности конструкций, организуемых глаголами интенционального воздействия, описание которой выходит за рамки поставленных в данной статье задач.

В группу глаголов интенционального воздействия входят следующие глаголы:

а. говорения (sagen, sprechen, behaupten...);

b. сообщения (mitteilen, informieren, berichten...);

c. убеждения (argumentieren, beweisen, belegen...);

d. побуждения (bitten, befehlen, auftragen...);

е. оценочного суждения (billigen, vorwerfen...);

f. обязательств (versprechen, schworen...);

g. социальной активности (danken, gratulieren...) и др.,

Следует отметить, что группа глаголов интенционального воздействия отличается некоторой гетерогенностью, обусловленной сложностью их смысловой структуры и многозначностью. Однако в состав группы тот или иной глагол входит не по всему своему смысловому объему, а только благодаря той части семантики, которая включает два названных выше компонента значения. Другая часть семантики группирует эти глаголы в иные лексические подсистемы.

Следовательно, рассматриваемая группа глаголов характеризуется открытостью, способностью функционировать в качестве единиц других лексико-семантических групп, что является организационной чертой языка и соответствует диалектическому характеру его внутрисистемных связей и отношений.

Ядро группы составляют глаголы говорения, сообщения и другие, в которых интенциональная (речевая) сема доминирует. Периферию образуют глаголы, занимающие промежуточное положение между глаголами психического состояния и физического действия. Это глаголы со значением социальной активности и институциональных действия: danken, protestieren, verbieten, fordern, aufrufen, erlauben...

Некоторые глаголы периферийной зоны могут в зависимости от контекста не реализовывать речевую сему: Er grüsste mich durch Kopfnicken

Характерной чертой глаголов интенционального воздействия является то, что при заполнении зависимых позиций они «могут иметь в роли дополнения только пропозиции и имена препозитивного значения, а в качестве своего субъекта-имена со значением живых существ» [1, с.128]. Если же позицию субъекта занимает предметное или пропозитивное, а не личностное имя, происходят 
сдвиги в семантике глагола:

1. Wir verlangten von allen also nur das, was wir selbst zu tun bereit waren;

2. Ein Milliardenobjekt wie IRO...verlangt, dass wir aus jeder Mark höchsten ökonomischen Nutzen ziehen;

3. Die Wirklichkeit in der Gegenwart verlangt von jedem Künstler... auf der Hohe der Zeit zu sein.

В примерах 2 и 3 предикат реализует не интенциональное значение, и может быть квалифицирован как глагол логического вывода.

Объектные позиции в конструкциях, организуемых глаголами интенционального воздействия, могут быть заполнены предикатные актанты различной структурной сложности:

1. пропозитивным именем (абстрактным именем или девербативом): Die palastinensische Mission hatte beim Präsidenten des Sicherheitsrates des Rederecht...

2. инфинитивным оборотом с «zu»: Sie fordere die NATO-Staaten auf, auf die Modernisierung von Waffen dieser Kategorie ebenfalls zu verzichten;

3. придаточным предложением с союзом dass или на w-форму: Ich sagte ihnen, dass ich ebenfalls darüber erschüttert bin Die Direktorin berichtete, wie das Kollektiv Neues in Angriff nahm.

Возникает вопрос, какие факторы влияют на различное поверхностно-синтаксическое оформление подобных конструкций? Ответ на него следует искать, повидимому, в трех направлениях.

Во-первых, на оформление предикатного актанта влияет семантика класса глаголов, что подтверждают исследования в этой области на материале языков различных типов, а также семная структура отдельных предикатов, требующих замещения зависимой объектной позиции пропозицией [7, с.8]. Семантика этих предикатов связана с названием деятельности, при помощи которой осуществляется фиксация.

Наряду с основной семой эти глаголы либо указывают на сам факт существования пропозиции, либо дают ей определенную оценку со стороны некоторого лица $[7, c .15]$. Причем обе разновидности комментаторы сем могут быть реализованы с одной и той же препозитивной:

1. Dieses Vorhaben, warnten amerikanische Fachleute, unterminiert die allgemeine Verbesserung der bilateralen Beziehungen zur Sowjetunion...;

2. Afghanische Regierung warnt vor neuen Aggressionsakten.

В первом случае предикат имеет модусное коммен- таторное значение, во втором-оценочное (каузетивное). Меняется и ролевая интерпритация предикатного актанта: в первом примере-это содержание предупреждения, во втором-каузируемое действие.

Следовательно, во-вторых, для поверхностно-синтаксического оформления предикатного актанта реливантно их синтаксическая роль в структуре предложения.

В-третьих, на оформление предикатного актанта влияют условия синтагматического согласования предложений в тексте.

Варьирующее замещение позиции предикатного актанта при глаголах интенционального воздействия характерно не только для разных лексико-семантических вариантов глагола. Оно наблюдается и в одном отдельно взятом лексико-семантическом варианте:

a. jmdn/jmdm lesen/das Lesen lehren;

b. er befahl mir, ihm zu folgen/dass ich ihm folgen sollte.

При этом возникает вопрос: можно ли считать вариантами приведенные словосочетания и конструкции? Признавая разницу между семантикой форм спрягаемого глагола, инфинитива и отглагольного имени и неправомерностью отнесения к вариантам взятых отдельно словоформ, едва л можно делать из этого вывод о существенной разнице в семантике параллельных словосочетаний и конструкций. Аргументом в пользу их трактовки как вариантов служит наличие «комплексного» инварианта, устанавливаемого общностью модели (глагол и предикатный актант), частичным тождеством субстанции, критерием взаимозаменяемости и главным образом общностью синтаксической семантики (две структурные пропозиции). Более принципиальным, однако, чем определение статуса данных словосочетаний и конструкций (варианты, синонимы, параллельные конкурирующие формы) является вопрос о пределах их варьирования и возможности выбора.

Вариативные замещения позиций предикатного актанта избирательны для каждого глагола:

3. abraten, auffordern, bewegen и т.д. могут употребляться с актантами в виде девербатива, инфинитивного оборота и придаточного предложения: Ich konnte inn nicht bewegen, diese Arbeit zu ubernehmen. - Ich konnte ihn zur Übernahme dieser Arbeit nicht bewegen - Ich konnte ihn dazu nicht bewegen, dass er diese Arbeit übernimmt;

4. sagen, sprechen, äußern и другие требуют в качестве пропозитивного дополнения девербатив или придаточное предложение:

Zum Abschluss äußerte er die Hoffnung auf eine Vertiefung der Kooperation - Zum Abschluss äußerte er, dass er auf eine Vertiefung der cooperation hofft... С указанными глаголами 
невозможен инфинитивный оборот: Zum Abschluss äußerte er, auf eine Vertiefung der Kooperation zu hoffen.

На выбор влияет также то обстоятельство, что запретов на трансформирование девербатива в инфинитивный оборот или придаточное предложение (с учетом избирательности преобразований для каждого глагола) довольно мало, в то время как инфинитив или спрягаемый глагол (сказуемое придаточного предложения) во многих случаях не может быть заменен девербативом. Таким преобразованиям препятствует целый ряд факторов, обусловленных:

а. словообразовательными возможностями лексемы в позиции сказуемого придаточного предложения;

b. нетождественностью значения главного глагола при трансформации;

с. невозможностью второго шага после номинации - адъективации приглагольных наречий; г) нетождественными синтаксическими и связями глагола и девербатива;

d. неоднозначностью семантики и синтаксических связей девербатива вследствие трансформации;

е. громоздкостью (большим объемом) придаточного предложения, и т.п.

Запрет на преобразование девербатива в инфинитив или спрягаемый глагол вызывает разрешение тождества производящей основы, а, следовательно, и идентичности обязательных валентностей; например: Auf dieser Situation antwortete unsere Regierung mit dem Afros: "Kampf um den Frieden - jetzt erst recht» - Auf diese Situation antwortete unsere Partei damit, dass sie aufgerufen hat...
Кроме этого, ряды словосочетаний и конструкций упомянутого вида подвергаются лексическим ограничениям; ср.: поручить выполнить - поручить выполнение, но приказать выполнить - приказать выполнение. Следовательно, если учесть эти ограничения, можно предположить, что все допустимые языковой нормой пары словосочетаний строятся в ряды грамматических вариантов. Это предположение, однако, неверно. Достаточно вспомнить оппозиции типа «люблю читать - люблю чтение», приведенные А.М. Пешковским, которые нормативны, но не могут считаться вариантами из-за разрушения инварианта (в структуре пропозиций) [9, с.49].

Исходя из вышесказанного следует, что тождество/ различие значений элементов пары зависит от значения доминирующего глагола и регулируется не узусом, а семантическими причинами. При этом доминирующую роль играют субкатекориальные, синтаксически релевантные значения слов, входящих в состав словосочетаний. Эти значения составляют область взаимодействия лексики и грамматики, которая лежит в основе всех синтаксических явлений и процессов и, в частности, определяет вариативность на семантическом уровне.

Таким образом, при рассмотрении варьирования в синтаксисе, предполагающем идентификацию предложения как виртуальной, так и актуальной единицы, возникающей в результате реализации определенной модели в акте речевой коммуникации, необходимо учитывать целый ряд семантических, структурно-синтаксических и текстообразующих факторов, отражающих вербоцентрическую природу предложения и условия внутреннего и внешнего синтагматического согласования предложений, то есть контекстов.

1. Арутюнова Н.Д. Предложение и его смысл. М., 1996.С128-129

ЛИТЕРАТУРА

2. Баклагова Ю.В. Каузатив. Средства выражения в русском и немецком языках// Культурная жизнь Юга России. г. Краснодар, 2008. С.114-116.

3. Богданов В.В. Семантико-синтаксическая организация предложения. Л., 1987. 204 с.

4. Кацнельсон С.Д. Общее и типологическое языкознание. Изд. 2, доп. 2010. 344 с.

5. Кацнельсон С.Д. Содержание слова, значение и обозначение. Изд. 3. 2011. 112 с.

6. Кацнельсон, С.Д. Типология языка и речевое мышление / С.Д. Кацнельсон. - М.: Эдиториал УРСС, 2009. 218с.

7. Кубрякова Е.С. О природе варьирования языковых единиц и его основных типах. // Проблема вариативности в германских языках: Тезисы доклада всесоюзной конференции/ М.,1989. С.25.

8. Леонтьев А.А. Психологические единицы и порождение речевого высказывания М., КомКнига, 2005 - 306с.

9. Пешковский А.М. Избранные труды / подгот. к печ., вступ. ст. и коммент. И.А. Василенко и И.Р. Палей. — М.: Учпедгиз, 1959. — 250 с.

10. Шведова Н.Ю. К понятию вариативности в языке. М., 1989. Т.42. №3С.239.

11. Ярцева В.Н. Проблема вариативности и взаимоотношениеи уровней грамматической системы языка// вопросы язык0знания. 1983. №5. С.21

12. Elsina Stubb, Wilhelm Von Humboldt's Philosophy of Language, Its Sources and Influence, Edwin Mellen Press, 2002. - 332p.

13. Frege G. Über Sinn und Bedeutung //Frege G. Funktion, Begriff, Bedeutung. Fünf logieche Studien. Göttingen, 1966. - S.47. 